Document downloaded from:

http://hdl.handle.net/10251/30373

This paper must be cited as:

Vercher Sanchis, JM.; Gil Benso, E.; Mas Tomas, MDLA.; Lerma Elvira, C. (2013).

Structural Flexural Bending Assessment of Prestressed Concrete Joist with Corrosion.

Advanced Materials Research. 790-793. doi:10.4028/www.scientific.net/AMR.671-674.790.

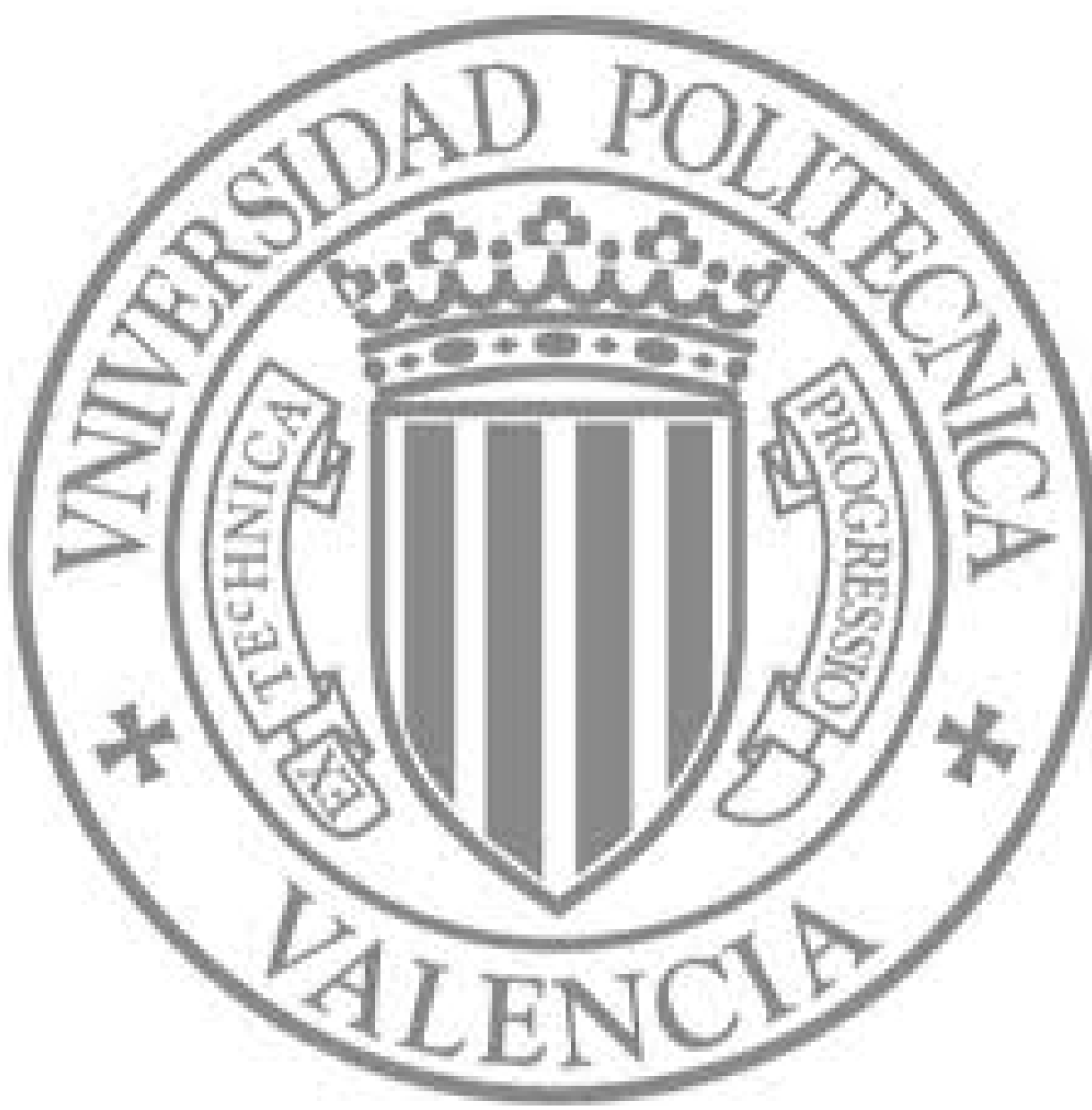

The final publication is available at

http://dx.doi.org/10.4028/www.scientific.net/AMR.671-674.790

Copyright Trans Tech Publications 


\title{
Structural Bending Assessment of Prestressed Concrete Joists with Corrosion
}

\author{
Jose Vercher ${ }^{1, \mathrm{a}}$, Enrique Gil ${ }^{1, \mathrm{~b}}$, Angeles Mas $^{1, \mathrm{c}}$ and Carlos Lerma ${ }^{1, \mathrm{~d}}$ \\ ${ }^{1}$ Polytechnic University of Valencia, Camino de Vera s/n, 46022 Valencia (Spain)

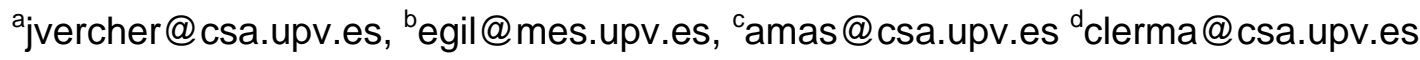

Keywords: Reliability, Corroded R/C Joist, Prestressed Joist, Load Test, Simulation until collapse.

\begin{abstract}
The number of situations where it is necessary to intervene in existing structures is increasing. In Spain, rehabilitation and maintenance of buildings accounts for $30 \%$ of the activity of the construction sector and it is growing. This paper evaluates the residual safety of $\mathrm{T}$ prestressed joists with severe corrosion at the lower reinforcement. The reliability is assessed with the application of the ACI-318 load test. It is demonstrated that there is sufficient safety in cases of corroded prestressed joists. At any rate, it's recommended to make a light repair under the damaged joists.
\end{abstract}

\section{Introduction}

The one-way concrete slabs, both prestressed and reinforced, are the most used in residential buildings in Spain. The slabs are the structural components that suffer more pathology. There have been some statistical studies on the causes of deterioration of structures. Nationally highlights the broad study by the Spanish Group of Concrete [1]. This study reveals that the structure type most affected by the deterioration is the $\mathrm{R} / \mathrm{C}$ one-way slabs, representing $68.0 \%$ of cases with pathology.

The aluminous cement was widely used in Spain during the massive construction from 1950 to 1970, especially for manufacturing prefabricated prestressed joists. The possibility of obtain a concrete with high resistance acquired early was an advantage. But, over time, this cement suffers conversion and concrete becomes more porous, whereby the reinforcement is more attackable.

The corrosion of the lower reinforcement is the most common pathology in slabs. The aim of this study is to evaluate the residual safety of a prestressed T-joist, when severe corrosion appears. In this paper a spacing between joists axes is evaluated. The set is formed by a prestressed joist and the concrete poured in situ, which completes the joist and the compression layer.

There are no studies evaluating the slab within the whole building. Generally simple elements are tested in bending, beams or joists. This is the case of Barbosa and Ribeiro [2], Fanning [3], and Coronelli and Gambarova [4]. Vercher's PhD [5] develops a work in which a complete slab as part of a residential building is evaluated.

\section{Methodology}

Nonlinear simulations of T-joists throughout their load range are performed using MEF. The models are made very accurately, with the real 3D geometry and the reinforcement in its exact position.

The materials nonlinearity is taken into account. Concrete can crack and crush, and the steel can yield. The materials are calibrated through simulations of studies of other professors $[2,3,4,6]$.

We obtain the load-vertical displacement curves at midspan for different models. The study of these curves allow us to evaluate the remaining safety in corroded specimens.

The used tools to assess the reliability are the ratio among the ultimate load and the service load, and the ACI-318 [7] load test.

\section{Studied specimens}

A prestressed T-joist of a one-way slab of $30 \mathrm{~cm}$ thickness is evaluated. In Fig. 1 we can see the actual constructive detail. The slab contains prefabricated prestressed joists, filler blocks, compression layer 
and flooring. The simulated model can be seen on the right side of Fig. 1. The mesh of the specimen is formed by $3 \mathrm{D}$ elements with a $3 \mathrm{~cm}$ edge.
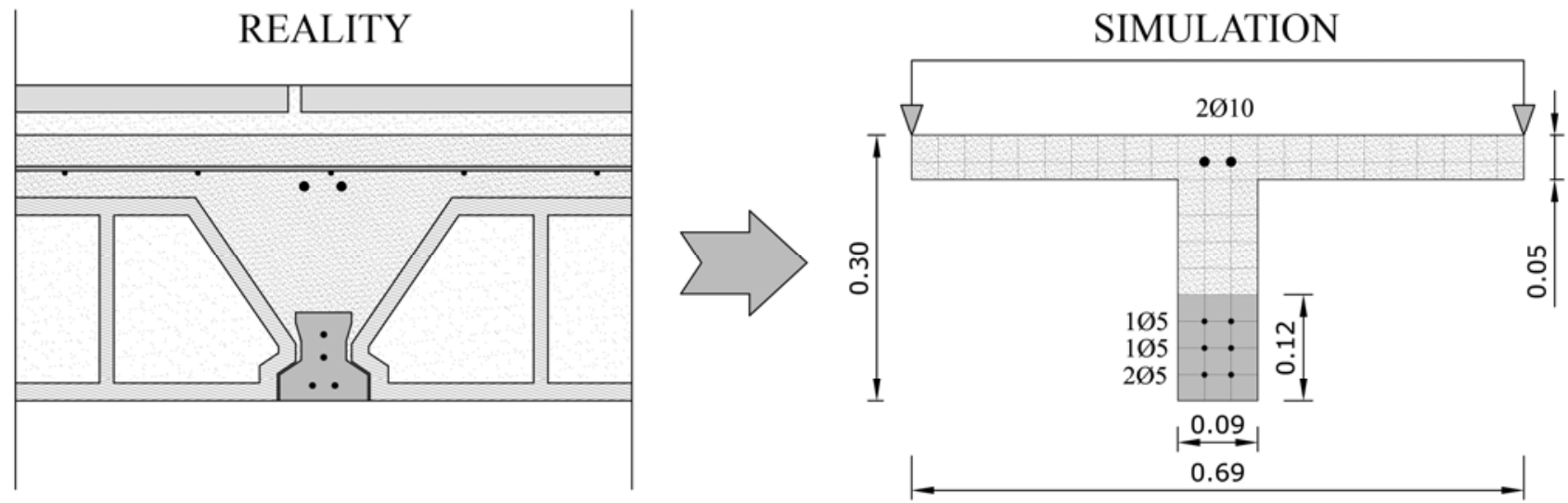

Fig. 1. Real and simulated T-joist

The simulated joist is part of a slab with a span of $4.92 \mathrm{~m}$ between column axes, with flat beams of $60 \mathrm{~cm}$ wide. Therefore the nerve length is $4.32 \mathrm{~m}$. The model is symmetric, so that we simulate half. A solid region has been modeled on the nerve end to simulate half flat beam $(30 \mathrm{~cm})$.

The compression layer is centered on the joist and it has $69 \mathrm{~cm}$ wide because this is the spacing between joists. Its thickness is $5 \mathrm{~cm}$.

The precast joist is built with high strength concrete (HP-40). The filler blocks are not simulated because they are not resistant elements. The poured concrete has usual features (HA-30).

The chosen prestressed joist is the T 12.3 of the Spanish company Prevalesa SL [8]. It has four prestressed wires on three different levels. These wires are made of high performance steel (Y-1860-C). In most cases corrosion only appears on the lower level, which is formed by 205 . The second and third level consists of 1Ø5. Each of these bars is simulated as two half area bars.

Furthermore, when the T-joist is part of a slab, it has negative reinforcement (2Ø10) and reinforcement mesh in the compression layer (\# $105 \mathrm{C} / 20$ ), formed by steel B-500-SD.

Table 1 shows the properties of the materials used in this investigation. $\beta_{t}$ and $\beta_{c}$ represent the values of the shear transfer coefficients in open and closed crack respectively. Conservative values that enable convergence and shear failure have been used.

\begin{tabular}{|c|c|c|c|c|c|c|c|c|c|}
\hline Material & & $\begin{array}{l}\rho \\
{\left[\mathrm{kN} / \mathrm{m}^{3}\right]}\end{array}$ & $\begin{array}{l}\mathrm{f}_{\mathrm{cm}} \\
{[\mathrm{MPa}]}\end{array}$ & $\begin{array}{l}\mathrm{E} \\
{[\mathrm{GPa}]}\end{array}$ & $\begin{array}{l}\mathrm{f}_{\mathrm{tm}} \\
{[\mathrm{MPa}]}\end{array}$ & $\begin{array}{l}\text { Poisson } \\
\text { Coefficient }\end{array}$ & $\beta_{\mathrm{t}}$ & $\beta_{\mathrm{c}}$ & $\begin{array}{l}\mathrm{f}_{\mathrm{y}} \\
{[\mathrm{MPa}]}\end{array}$ \\
\hline \multirow[t]{2}{*}{ Concrete } & HA-30 & 25 & 38 & 28.6 & 3.39 & 0.20 & 0.15 & 0.6 & - \\
\hline & HP-40 & 25 & 48 & 30.9 & 3.96 & 0.20 & 0.15 & 0.6 & - \\
\hline \multirow[t]{2}{*}{ Steel } & B-500-SD & 78.5 & - & 200 & - & 0.30 & - & - & 500 \\
\hline & Y-1860-C & 78.5 & - & 200 & - & 0.30 & - & - & 1581 \\
\hline
\end{tabular}

Table 1. Material properties

The simulation of the process of loads and order of appearance of structural and building elements is very important, to get the results as realistic as possible. Because of this, we have simulated a series of load steps, which are as follows:

- The prestressed joists are built in the factory. In a first load step, only the elements representing the $12 \mathrm{~cm}$ joist are active. Equivalent prestressing loads are applied, according to the distributor. Due to the prestressing forces, the joist has an initial negative deflection.

- In a second load step, the poured in situ concrete appears (HA-30). 
- When the geometry is completed, we load the T-joist to service load. The service load is the load to which it is subjected the major part of its life. It consists of the dead loads and the quasi-permanent part of overloading, according to CTE-06 [9]. The housing overload has a characteristic value of $2000 \mathrm{~N} / \mathrm{m}^{2}$ in Spain. The dead load of the slab is $3500 \mathrm{~N} / \mathrm{m}^{2}$, the flooring weight is $1000 \mathrm{~N} / \mathrm{m}^{2}$, the weight of the partition walls is $1000 \mathrm{~N} / \mathrm{m}^{2}$, and the quasi-permanent value of the overload is $600 \mathrm{~N} / \mathrm{m}^{2}$. Therefore, the service load is $6100 \mathrm{~N} / \mathrm{m}^{2}$. It is represented by a horizontal dotted line in Fig. 2.

- In the following load step, the corrosion is simulated.

- Finally, in a last load step, the T-joist is loaded until collapse.

\section{Results}

The prestressed joists simulation throughout their load range has been performed. To evaluate the reliability, load-vertical displacement curves at midspan are compared in healthy and corroded models (Fig. 2). Different boundary conditions are simulated to analyze the real behavior of T-joist.

Table 2 explains the simulated specimens and the ultimate load and displacement for each model.

\begin{tabular}{|c|c|c|c|c|}
\hline Specimen & & & $\begin{array}{r}\text { Ultimate Load } \\
{\left[\mathrm{N} / \mathrm{m}^{2}\right]}\end{array}$ & $\begin{array}{r}\text { Vertical Displacement } \\
\qquad[\mathrm{cm}]\end{array}$ \\
\hline \multirow[t]{2}{*}{ Two-hinged joist } & Uncorroded & A1 & 10454 & 0.03 \\
\hline & Corroded & $\mathrm{A} 2$ & 7866 & 0.05 \\
\hline \multirow[t]{2}{*}{ Fixed-ended joist } & Uncorroded & $\mathrm{B} 1$ & 40406 & 0.16 \\
\hline & Corroded & B2 & 42515 & 0.22 \\
\hline
\end{tabular}

Table 2. Results from different simulated specimens

ACI-318 [7] discloses a load test to determine if an existing structure can remain in use. The steps we must follow, that are shown in Fig. 2, are:

- Total load value: $Q_{t}=0.85(1.4 D+1.7 L)$, where $D$ is the sum of dead loads $\left(5500 \mathrm{~N} / \mathrm{m}^{2}\right)$ and $L$ is the sum of the overloads $\left(2000 \mathrm{~N} / \mathrm{m}^{2}\right)$. In the simulated cases, the total load is $9435 \mathrm{~N} / \mathrm{m}^{2}$.

- We have to measure the deflection increase produced from the only existence of dead loads until the total load value of $9435 \mathrm{~N} / \mathrm{m}^{2}$ in this case.

- This deflection increase is limited to $l_{t}^{2} /(20000 h)$, where $l_{t}$ is the slab span between column axes, $4.92 \mathrm{~m}$ in the studied case, and $h$ is the slab thickness, $30 \mathrm{~cm}$. The deflection increase limit is $4.03 \mathrm{~mm}$.

\section{Conclusions}

A joist with severe corrosion can stand, as observed in real cases of pathology in which do not appear excessive cracking or deflections. Cases of isolated prestressed T-joist with complete corrosion at lower reinforced may continue in use, according to ACI-318, due to an increased deflection lower than $4.03 \mathrm{~mm}$, with the exception of the corroded two-hinged joist.

In the case of the fixed-ended joist, the collapse is not governed by the bending, although a severe corrosion at prestressed lower wires appears. The collapse occurs at similar loads $\left(\approx 41000 \mathrm{~N} / \mathrm{m}^{2}\right)$ in the healthy and corroded case. The models are able to find the balance for the entire load range of the curves in Fig. 2 due to the upper prestressed healthy wires and the undeformability of the boundary conditions. The collapse occurs of a brittle manner due to mechanisms associated with shear.

Furthermore, in the case of the two-hinged joist, the only way to balance the section when there is severe corrosion at the lower reinforcement is by the remaining healthy wires. These wires still manage to balance a quite high load. 
Inside a slab, the joists are between boundary conditions for theoretical cases, and they work together. In this case also can be obtained sufficiently accurate simulations (see Vercher's PhD).

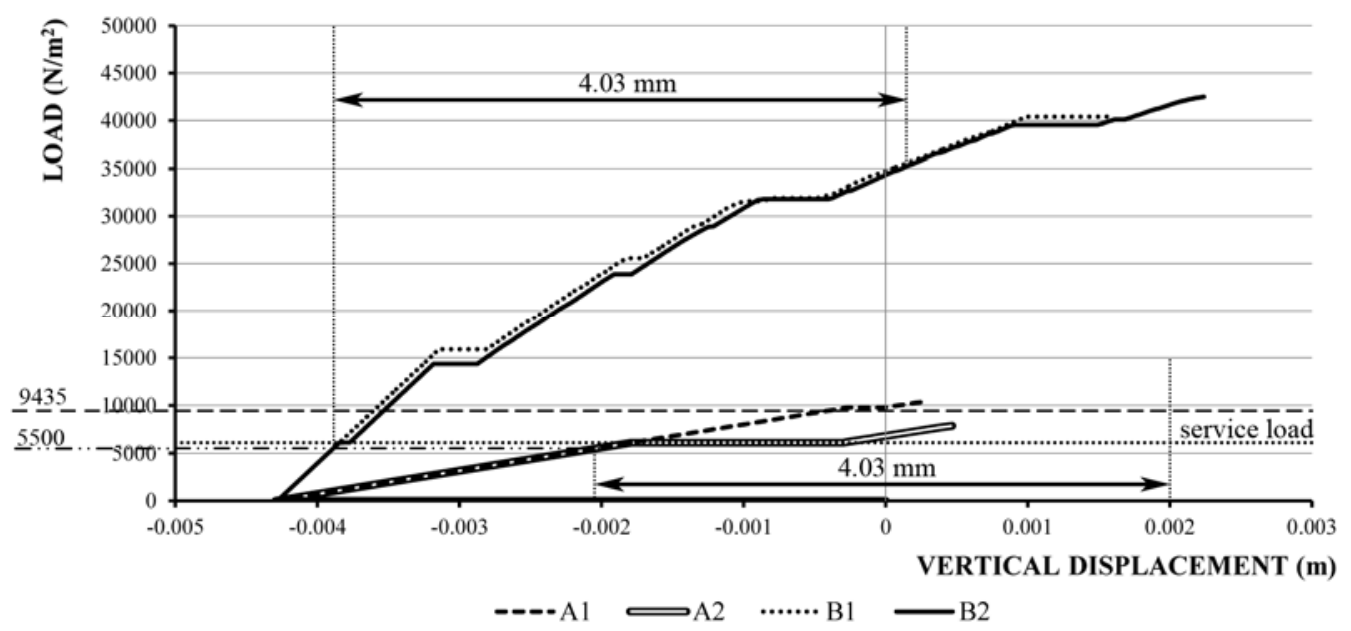

Fig. 2. Load-vertical displacement curves

One aspect that stands out is that when simulating the corrosion in a $\mathrm{R} / \mathrm{C}$ joist, the nerve collapses. In contrast, the prestressed joist has some capacity after the corrosion of lower reinforcement. This is because there are more wire levels. The prestressed joist has greater remaining capacity.

When a joist is constrained, there are additional resistance mechanisms, such as the arch, which help support the loads.

It is necessary to make a careful shear study. The brittle failure must be avoided. In this work, with regular spans around $5 \mathrm{~m}$, the shear causes the collapse in cases of fixed-ended joists.

Anyway, it is always recommended repair damaged joists, restoring the capacity searched in design phase. A lower reinforcement fiber bands is sufficient in these cases.

\section{References}

[1] Grupo Español del Hormigón (GEHO): Encuesta sobre patología de estructuras del hormigón, edited by Boletín GEHO Vol. 10, Madrid (1992)

[2] A.F. Barbosa and G.O. Ribeiro: Analysis of reinforced concrete structures using Ansys nonlinear concrete model. Computational Mechanics Vol. 1 n.8 (1998), p. 1-7

[3] P. Fanning: Nonlinear models of reinforced and post-tensioned concrete beams. Electronic Journal of Structural Engineering Vol. 2 (2001), p. 111-119

[4] D. Coronelli and P. Gambarova: Structural assessment of corroded reinforced concrete beams: modeling guidelines. Journal of Structural Engineering Vol. 130 n.8 (2004), p. 1214-1224

[5] J. Vercher: Seguridad residual en los forjados con corrosion severa. PhD. Department of Architectural Constructions. Polytechnic University of Valencia (2013)

[6] T. Tavio and A. Tata: Predicting nonlinear behavior and stress-strain relationship of rectangular confined reinforced concrete columns with Ansys. Civil Engineering Dimension Vol. 11 (2009)

[7] American Concrete Institute (ACI): Building Code Requeriments for Structural Concrete (ACI 318-08) and Commentary. Strength Evaluation of Existing Structures. Michigan, USA (2008)

[8] Prevalesa S.L.: Ficha de características técnicas - según EHE-08 - del forjado de viguetas pretensado modelo DITECO T12. Valencia, Spain (2008)

[9] Ministerio de Vivienda: Código Técnico de la Edificación (CTE), edited by Boletín Oficial del Estado, Madrid (2006) 